Article

\title{
Evaluation of Workability and Mechanical Properties of Bottom Ash Aggregate Concrete
}

\author{
Yong-Hyok Kim ${ }^{1}\left(\mathbb{D}\right.$, Hak-Young Kim ${ }^{2, *} \mathbb{C}$, Keun-Hyeok Yang ${ }^{2} \mathbb{D}$ and Jung-Soo Ha ${ }^{3}$ \\ 1 Resource Recycling Research Center, Korea South-East Power CO., Incheon 23120, Korea; \\ yhkim@koenergy.kr \\ 2 Department of Architectural Engineering, Kyonggi University, Suwon 16227, Gyonggi-do, Korea; \\ yangkh@kgu.ac.kr \\ 3 Department of Architectural Engineering, Dankook University, Yongin-si 448-701, Gyeonggi-do, Korea; \\ jungsha11@dankook.ac.kr \\ * Correspondence: concrete@kgu.ac.kr
}

Received: 29 October 2020; Accepted: 11 November 2020; Published: 12 November 2020

\begin{abstract}
The purpose of this study is to evaluate the workability and mechanical properties of concrete containing bottom ash, which is an industrial byproduct, as an aggregate. Twelve concrete mixtures, including concrete containing bottom ash aggregate (CCBA), are classified into three groups of $W / C 0.45,0.375$, and 0.3 according to the target strength. Each group includes four mixtures in which natural aggregate and bottom ash are applied as fine and coarse aggregates according to particular ratios. On the basis of the test results, a reliable model to predict the 28-day compressive strength of CCBA is proposed by applying regression analysis. The proposed model points out that when applying bottom ash as aggregate, the concrete density is lowered, and $W / C$ should be reduced to offset the lowered compressive strength. As a result of comparing experimental values with the existing design code models, it is found that while the fib model accurately predicts compressive strength development and tensile resistance capacity in general, the ACI 318 code overestimates the elastic modulus at the oven-dried density $\left(\rho_{c}\right)$ range of $1840 \mathrm{~kg} / \mathrm{m}^{3}$ and above. Accurate prediction of the mechanical properties of CCBA requires the measurement of additional experimental data that consider $W / C$ and $\rho_{c}$ as important parameters.
\end{abstract}

Keywords: bottom ash; lightweight concrete; density; workability; mechanical properties

\section{Introduction}

In South Korea, the amount of industrial waste has been increasing exponentially for decades due to rapid growth and industrial expansion. In this context, many studies have contributed to improvement of the physical and mechanical properties of concrete by adding recycled industrial waste. As a result, a number of industrial byproducts (e.g., fly ash (FA), silica fume, and blast furnace slag) have been recognized as concrete admixture additives, and are widely used [1]. On the other hand, byproducts from marine sediment, municipal solid waste incinerator (MSWI), and bottom ash (BA) show noticeably low rates of utilization due to their respective drawbacks [2,3]. Among them, the use of BA, which accounts for $10-15 \%$ of the total amount of cinders generated, shows significantly less improvement in the mechanical characteristics of concrete compared to FA [4]. Thus, the demand for it is low, and most BA beyond storage capacity is buried or discarded [5,6]. BA contains heavy metals and arsenic as part of its chemical composition, and is classified as an environmental hazard in the majority of countries $[7,8]$. Therefore, it is necessary to accurately evaluate the mechanical properties of BA-incorporated concrete in order to achieve a concrete structure that is safe, durable, and sustainable. 
BA is generally considered to be most appropriate for use as an alternative to fine aggregate in concrete. In a considerable number of studies, the use of BA as an alternative to fine aggregate revealed very encouraging results in terms of strength and pore structure [9-12]. Some studies have reported that there is an increase in strength compared with plain concrete according to the replacement ratio of fine bottom ash aggregate (BAA) [13-15], and indicate that this is most probably caused by the pozzolanic reaction of particles $600 \mu \mathrm{m}$ or less in size among the BAA [16]. Coarse BAA is porous, irregular, angular, and rough-textured, and is characterized by being lighter than natural aggregate $[17,18]$. These physical properties may be suitable for the application of coarse BAA as concrete aggregate; however, its excessively porous structure and rough-textured properties act as disadvantages that may lower the mechanical properties of concrete, including fluidity and strength development. In particular, BAA shows a lower density than natural aggregate at about $2.0 \mathrm{~kg} / \mathrm{m}^{3}$ (although it varies according to producing countries and manufacturing technologies), and so is classified as lightweight aggregate (LWA), but it is a relatively heavy LWA. In general, concrete containing bottom ash (CCBA) has a relatively higher density than the range of oven-dried density $\left(\rho_{c}\right)\left(1600-1840 \mathrm{~kg} / \mathrm{m}^{3}\right)$ for lightweight aggregate concrete (LWAC) suggested by LWAC-related design codes (ACI Committee 213 [19], ASTM C 330 [20], and Comité Euro-International du Beton [21]).

For the reliable design of structures, specific data and rational estimation regarding the mechanical properties of materials are required. In general, LWAC is known to show inferior mechanical performance compared to normal weight concrete (NWC) with similar compressive strength. If the strength of the aggregate itself is low, the transmission velocity of the cracks becomes high because cracking in the case of maximum load mostly penetrates the aggregate, and a large decrease in strength occurs in parts of the same member because of the generation of localized failure zones [17].

The biggest obstacle to the use of CCBA for structures is that there are relatively few studies on its mechanical properties. Accordingly, it is difficult to clearly determine its adherence to the existing structural design codes. These concerns are greater when BA is applied as coarse aggregate than as fine aggregate $[12,22]$. This study used four types of aggregate: all-lightweight aggregate concrete (A-LWAC, $R_{S}=R_{G}=0 \%$ ), sand-lightweight aggregate concrete (S-LWAC, $R_{S}=0 \% R_{G}=100 \%$ ) gravel-lightweight aggregate concrete (G-LWAC, $R_{S}=100 \% R_{G}=0 \%$ ), to which BAA was applied, and NWC $\left(R_{S}=R_{G}=100 \%\right)$, to which natural aggregate was applied. (Here, $R_{S}$ and $R_{G}$ denote the ratios of natural aggregate replacing fine and coarse BAA, respectively.) Further, this study specified three values of $W / C$, the most important determinant of mechanical properties, and conducted an evaluation of 12 concrete mixtures. In fresh concrete, the initial slump, air content, and segregation were measured, and in hardened concrete, the following items were measured: compressive strength development, the modulus of elasticity $\left(E_{c}\right)$ and rupture $\left(f_{r}\right)$, splitting tensile strength $\left(f_{s p}\right)$, and shear friction strength $(\tau)$. To ensure the reliability of the experimental results and the equations proposed from them, comparisons were carried out with previous studies [17,23] as well as ACI 318-14 [24] and the fib model [21]. Unlike ACI 318-14 [24] applicable to all sorts of structural concrete including NWC, the fib model [21] presents a coefficient and $\rho_{c}$ according to aggregates' own strength as a parameter for predicting performance of concrete. The previous study of Lee et al.'s $[17,23]$ adopted $\rho_{c}$ and $R_{S}$, and $R_{G}$ of LWAC as one of critical prediction variables, and it has a high similarity with this study in terms of the regression analysis method of experiment results.

\section{Significance of Research}

This study includes equations developed on the basis of experimental data and regression analysis to comprehensively evaluate the various mechanical properties of concrete using bottom ash, an industrial byproduct. The results demonstrate that the mechanical properties of lightweight concrete have high correlations with $\rho_{c}$ as well as compressive strength (or W/C). This study has derived results of more conservative and consistent applicability than the existing design codes by applying the CCBA design equations verified by a number of previous studies. 


\section{Experimental Details}

\subsection{Materials}

The ordinary Portland cement (OPC), which was applied to all concrete test specimens, had a density of $3.15 \mathrm{~g} / \mathrm{cm}^{3}$ and a specific surface area of $3260 \mathrm{~cm}^{2} / \mathrm{g}$. Its other properties fulfilled the standards for ASTM type I [25]. The BAA used in the experiment was air-cooled while it passed on a mobile belt installed at the bottom of the coal furnace, and then processed into an appropriate grain size through crushing and grinding. The main components of BAA, as measured by X-ray diffraction, were quartz and calcium aluminum silicate (see Figure 1 and Table 1), similar to the raw materials of coal ash. The grain shape of BAA shows irregular and rough surface characteristics, as seen in Figure 2a,b. BAA has a high degree of porosity both on its external surface and in the core of the grains. In particular, the porosity in the core is generally formed with a closed porous structure, whereas the porosity in the parts of the core close to the external surface is connected to the porosity on the external surface. Maximum sizes of $20 \mathrm{~mm}$ and $4 \mathrm{~mm}$ were used for coarse and fine BAA, respectively, and the range of sizes was adjusted to satisfy the particle distribution curve specified in ASTM C 330 [20]. Locally available crushed granite and natural sand were used as the normal-weight coarse and fine aggregates, respectively. The physical properties of the aggregates used in the experiment are shown in Table 2.

Table 1. Chemical composition of aggregates used.

\begin{tabular}{ccccccc}
\hline Type & $\mathrm{SiO}_{2}$ & $\mathrm{Al}_{2} \mathrm{O}_{3}$ & $\mathrm{Fe}_{2} \mathrm{O}_{3}$ & $\mathrm{CaO}$ & $\mathbf{M g O}$ & $\mathrm{SO}_{3}$ \\
\hline Bottom ash aggregate & 46.1 & 17.8 & 16.0 & 10.3 & 1.7 & 0.1 \\
Natural sand & 73.4 & 13.0 & 2.9 & 1.4 & - & - \\
\hline
\end{tabular}

Table 2. Physical properties of aggregates used.

\begin{tabular}{cccccc}
\hline \multirow{2}{*}{ Aggregate Type } & & $\begin{array}{c}\text { Maximum } \\
\text { Size }(\mathbf{m m})\end{array}$ & $\begin{array}{c}\text { Density } \\
\left(\mathbf{g} / \mathbf{c m}^{\mathbf{3}}\right)\end{array}$ & $\begin{array}{c}\text { Water } \\
\text { Absorption (\%) }\end{array}$ & $\begin{array}{c}\text { Fineness } \\
\text { Modulus }\end{array}$ \\
\hline \multirow{2}{*}{ Natural aggregate } & Coarse & 25 & 2.62 & 1.1 & 6.41 \\
& Fine & 5 & 2.6 & 2.1 & 2.90 \\
\hline \multirow{2}{*}{ Bottom ash aggregate } & Coarse & 20 & 1.84 & 12.1 & 6.58 \\
& Fine & 4 & 2.08 & 9.7 & 2.93 \\
\hline
\end{tabular}

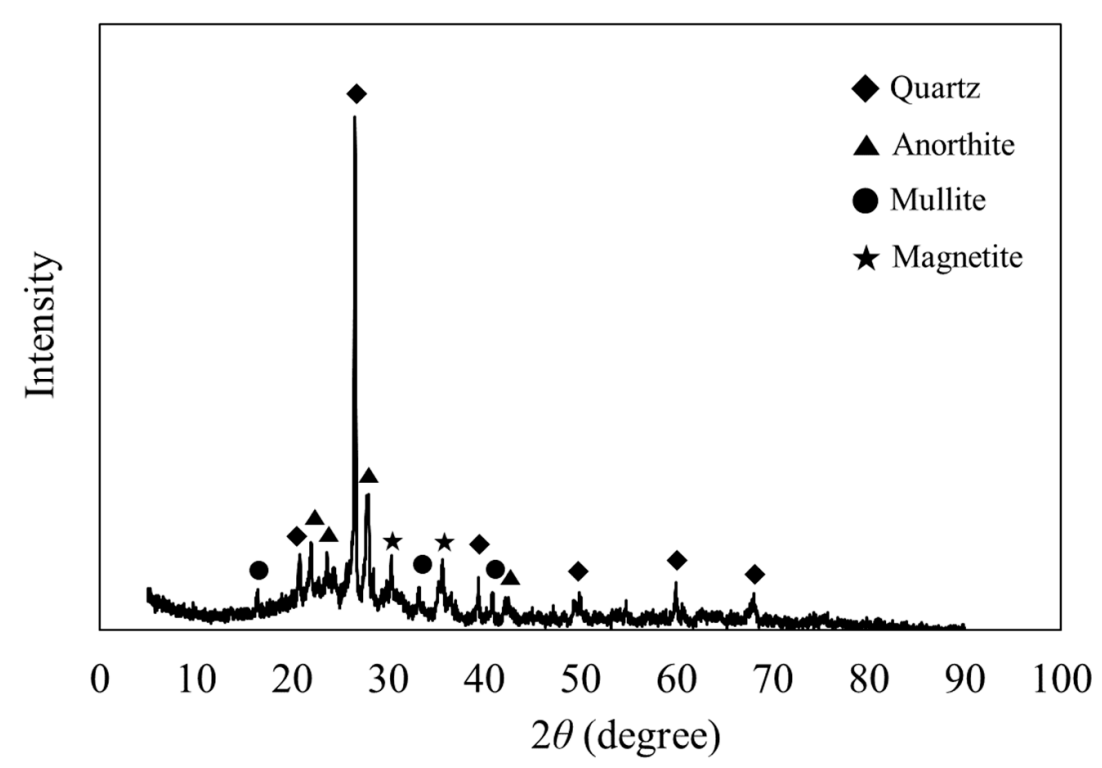

Figure 1. X-ray diffraction patterns of the bottom ash aggregates used. 


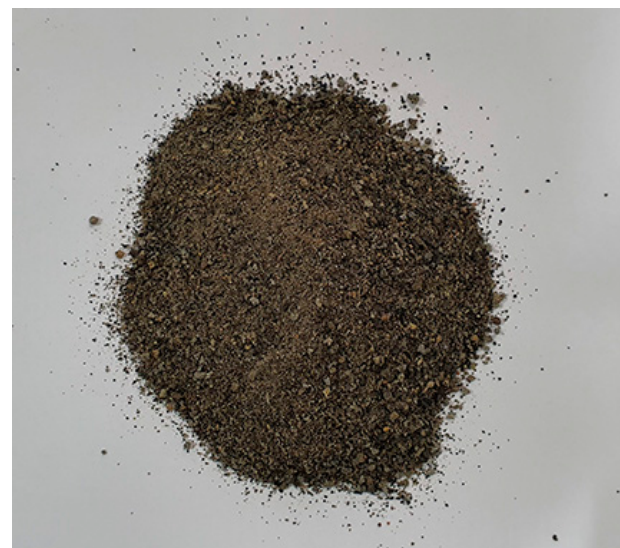

(a) Typical shape (below $2 \mathrm{~mm}$ )

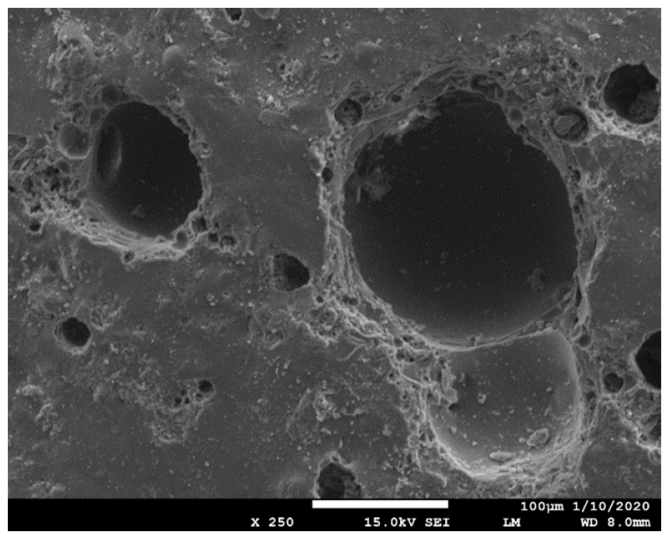

(c) External surface $(\times 250)$

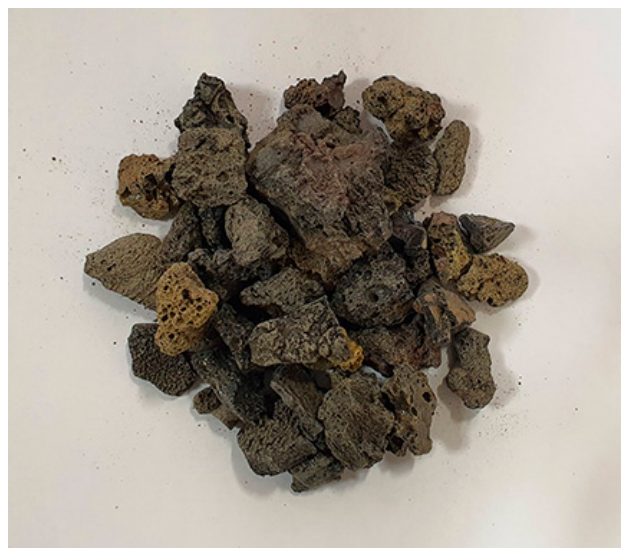

(b) Typical shape (10-20 mm)

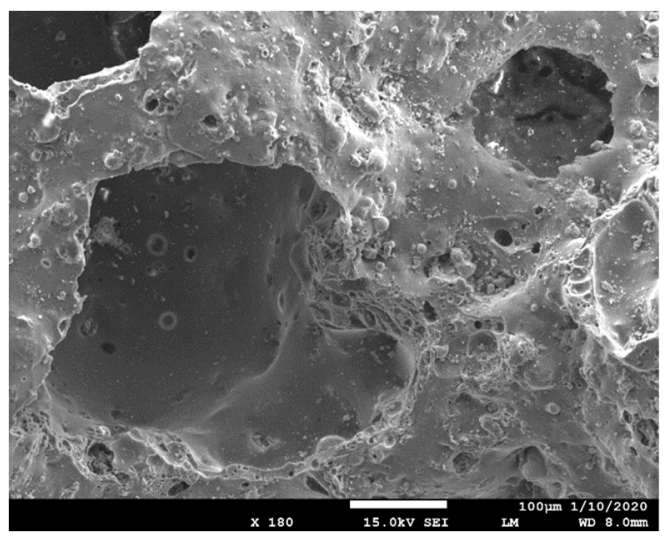

(d) Internal microstructure $(\times 180)$

Figure 2. Shapes and scanning electron microscopy (SEM) images of bottom ash aggregates.

\subsection{Concrete Mixtures}

Table 3 shows the mixture proportions of concrete according to the design variables. The major variables are unit cement content based on $W / C$ and the types of fine and coarse aggregates. A total of 12 designed concrete mixes are classified into the following three groups according to W/C: 0.45 (group L), 0.375 (group M), and 0.3 (group H). The first letter of the name of each specimen refers to the group symbol, the second letter to $R_{S}$, and the third letter to $R_{G}$, respectively. $R_{S}$ and $R_{G}$ refer to the ratios of the replacement of fine and coarse BAA with natural sand and crushed granite, respectively. For example, specimen L-100-0 indicates a mixture in L group $(W / C=0.45)$, whose designed compressive strength $\left(f_{c d}\right)$ is relatively low, for which natural sand is used in the case of fine aggregate and BAA is used in the case of coarse aggregate. In addition, $\mathrm{H}-0-0$ indicates a mixture with $W / C$ of 0.3 , and for which BAA is used for both fine and coarse aggregates. In all the mixtures, the fine aggregate ratio $(S / a)$ and unit water content $(W)$ were fixed at $45 \%$ and $175 \mathrm{~kg} / \mathrm{m}^{3}$, respectively. BAA was immersed in water for $48 \mathrm{~h}$ before use in the experiment, and then dried in a shaded environment until it entered the saturated surface-dry state. This was done because, when using LWA with high water absorption, the water needed for the hydration of the cement can be absorbed due to the high porosity inside the aggregate, which affects the mechanical properties of concrete after its hardening. A commercially available, polycarboxylate-based, water-reducing admixture was added to $0.6 \%$ of the cement mass content. 
Table 3. Mixture proportions of concrete.

\begin{tabular}{|c|c|c|c|c|c|c|c|c|c|}
\hline \multirow{2}{*}{ Specimens } & \multirow{2}{*}{$W / C$} & \multirow{2}{*}{$R_{S}(\%)$} & \multirow{2}{*}{$R_{G}(\%)$} & \multicolumn{6}{|c|}{ Unit Volume Weight $\left(\mathrm{kg} / \mathrm{m}^{3}\right)$} \\
\hline & & & & $W$ & $C$ & $F_{S}$ & $F_{B}$ & $C_{G}$ & $C_{B}$ \\
\hline L-0-0 & \multirow{4}{*}{0.45} & 0 & 0 & \multirow{12}{*}{175} & \multirow{4}{*}{389} & 0 & 614 & 0 & 654 \\
\hline L-100-0 & & 100 & 0 & & & 756 & 0 & 0 & 654 \\
\hline L-0-100 & & 0 & 100 & & & 0 & 614 & 932 & 0 \\
\hline L-100-100 & & 100 & 100 & & & 768 & 0 & 946 & 0 \\
\hline M-0-0 & \multirow{4}{*}{0.375} & 0 & 0 & & \multirow{4}{*}{467} & 0 & 590 & 0 & 629 \\
\hline M-100-0 & & 100 & 0 & & & 728 & 0 & 0 & 629 \\
\hline M-0-100 & & 0 & 100 & & & 0 & 590 & 896 & 0 \\
\hline M-100-100 & & 100 & 100 & & & 739 & 0 & 910 & 0 \\
\hline H-0-0 & \multirow{4}{*}{0.3} & 0 & 0 & & \multirow{4}{*}{583} & 0 & 555 & 0 & 592 \\
\hline H-100-0 & & 100 & 0 & & & 684 & 0 & 0 & 592 \\
\hline H-0-100 & & 0 & 100 & & & 0 & 555 & 843 & 0 \\
\hline H-100-100 & & 100 & 100 & & & 696 & 0 & 857 & 0 \\
\hline
\end{tabular}

Note: $R_{S}=$ natural sand content ratio for the replacement of fine bottom ash aggregates; $R_{G}=$ natural crushed granite content ratio for the replacement of coarse bottom ash aggregates; $F_{S}=$ natural sand; $F_{B}=$ fine bottom ash aggregate; $C_{G}=$ natural crushed granite; $C_{B}=$ coarse bottom ash aggregate.

\subsection{Casting, Curing, and Testing}

The initial slump and air contents of the freshly mixed concrete were tested according to ASTM C143 [26] and ASTM C231 [27], respectively. The compressive and splitting tensile strengths and elasticity modulus of concrete were measured using $100 \times 200 \mathrm{~mm}$ cylinder specimens. A compressor meter equipped with two 5-mm linear variable differential transformers was mounted on the cylinder specimens to record the concrete strain according to the applied loads. In accordance with ASTM C469 [28], the modulus of elasticity of concrete was calculated as the slope of the secant line joining zero stress and $40 \%$ peak stress. The modulus of rupture of the concrete was measured using prismatic beams with dimensions of $100 \times 100 \times 400 \mathrm{~mm}$. In addition, the shear friction strength of the concrete specimens was recorded by push-off tests under a concentric load acting as pure shear in the shear plane of the test zone. The push-off specimens had width, height, depth, and critical shear plane area of $300 \mathrm{~mm}, 800 \mathrm{~mm}, 120 \mathrm{~mm}$, and $200 \times 120 \mathrm{~mm}$, respectively. The compressive strength of the concrete was recorded at ages of 1, 3, 7, 28, 56 and 91 days, whereas the other mechanical properties were measured at 91 days. To verify the segregation of the concrete, digital image analysis was conducted. The $100 \times 200 \mathrm{~mm}$ cylinder was cut longitudinally, and images of the cutting plane were captured using a high-resolution digital camera. The grayscale contrast between BA particles, granite particles, and paste was profiled via image analysis of all quarter zones of the cutting plane. The area of aggregate particles in each quarter zone was recorded from the image analysis to calculate the proportion of each component.

\section{Results and Discussion}

\subsection{Initial Slump $\left(S_{i}\right)$ and Air Content $\left(v_{A}\right)$}

The results of the initial slump $S_{i}$ and air contents $v_{A}$ for specimens in which the water-reducing agent was mixed in equal proportion to cement weight are shown in Table 4. A-LWAC showed the lowest slump value when using BAA as both fine aggregate and coarse aggregate at the same W/C, and a medium value when using BAA only as either fine aggregate or coarse aggregate. In general, a number of researchers have reported that the slump is decreased when using BAA instead of natural aggregate [29]. This indicates that the influence of the physical properties of BAA, such as its irregular shape and rough surface texture, are the greatest. In addition, some studies have reported that for fine BAA, $R_{S}$ has a greater influence on the slump than $R_{G}$ because it contains a large percentage of particles $600 \mu \mathrm{m}$ or below in radius that are difficult to accurately control in the process of grain size 
adjustment [16]. The results of the present experiment also show a greater decline in slump when using BAA as fine aggregate than as coarse aggregate.

The air contents of all the specimens were not greatly affected by $R_{S}, R_{G}$, or $W / C$, as shown in Table 4. The air content of all specimens was within 4.0-5.5\%, and met the recommended requirements of LWAC not exposed to freezing [19].

Table 4. Summary of the test results.

\begin{tabular}{|c|c|c|c|c|c|c|c|c|c|c|c|c|}
\hline \multirow{2}{*}{ Specimens } & \multirow{2}{*}{$\begin{array}{c}S_{i} \\
(\mathrm{~mm})\end{array}$} & \multirow{2}{*}{$\begin{array}{c}v_{A} \\
(\%)\end{array}$} & \multirow{2}{*}{$\begin{array}{c}\rho_{c} \\
\left(\mathrm{~kg} / \mathrm{m}^{3}\right)\end{array}$} & \multicolumn{5}{|c|}{$f_{c}(t)(\mathrm{MPa})$} & \multirow{2}{*}{$\begin{array}{c}f_{s p} \\
\text { (MPa) }\end{array}$} & \multirow{2}{*}{$\begin{array}{l}f_{r} \\
(\mathbf{M P a})\end{array}$} & \multirow{2}{*}{$\begin{array}{c}E_{c} \\
\text { (MPa) }\end{array}$} & \multirow{2}{*}{$\begin{array}{c}T \\
(\mathrm{MPa})\end{array}$} \\
\hline & & & & $\begin{array}{c}3 \\
\text { Days }\end{array}$ & $\begin{array}{c}7 \\
\text { Days }\end{array}$ & $\begin{array}{c}28 \\
\text { Days }\end{array}$ & $\begin{array}{c}56 \\
\text { Days }\end{array}$ & $\begin{array}{c}91 \\
\text { Days }\end{array}$ & & & & \\
\hline L-0-0 & 145 & 4.2 & 1703 & 15.0 & 18.3 & 23.3 & 25.4 & 27.9 & 2.34 & 3.93 & 18,082 & 4.30 \\
\hline L-100-0 & 165 & 5.0 & 1823 & 18.1 & 24.5 & 27.5 & 29.2 & 31.2 & 2.96 & 4.69 & 21,483 & 5.00 \\
\hline L-0-100 & 155 & 4.8 & 2015 & 18.1 & 28.1 & 36.4 & 39.8 & 42.1 & 3.29 & 4.97 & 22,208 & 5.98 \\
\hline L-100-100 & 175 & 4.7 & 2173 & 23.0 & 31.6 & 39.2 & 40.2 & 44.7 & 3.65 & 4.91 & 22,223 & 6.39 \\
\hline M-0-0 & 150 & 4.9 & 1775 & 18.9 & 20.2 & 29.5 & 28.0 & 31.0 & 3.28 & 4.85 & 22,493 & 5.50 \\
\hline M-100-0 & 165 & 5.1 & 1852 & 23.7 & 23.4 & 30.6 & 34.5 & 38.0 & 3.28 & 5.20 & 22,058 & 4.79 \\
\hline M-0-100 & 150 & 5.2 & 2066 & 25.1 & 33.4 & 42.8 & 46.0 & 48.7 & 3.48 & 5.81 & 25,572 & 5.77 \\
\hline M-100-100 & 170 & 4.8 & 2220 & 27.1 & 33.2 & 46.1 & 48.0 & 48.9 & 3.64 & 6.16 & 25,410 & 7.39 \\
\hline H-0-0 & 135 & 4.8 & 1840 & 28.4 & 35.9 & 41.3 & 44.6 & 43.0 & 3.80 & 5.55 & 23,072 & 4.45 \\
\hline H-100-0 & 155 & 5.0 & 1952 & 25.5 & 32.0 & 40.7 & 42.2 & 43.9 & 3.77 & 4.54 & 22,316 & 5.22 \\
\hline H-0-100 & 155 & 5.2 & 2171 & 30.0 & 43.1 & 52.6 & 53.1 & 55.9 & 3.95 & 6.00 & 27,877 & 7.03 \\
\hline H-100-100 & 160 & 5.5 & 2334 & 30.5 & 42.7 & 52.1 & 50.1 & 55.6 & 4.11 & 6.16 & 27,419 & 6.79 \\
\hline
\end{tabular}

\subsection{Segregation}

Due to its relatively low weight, BAA may incur segregation or floating in the process of mixing fresh concrete. Figure 3 shows the typical distribution of lightweight aggregate particles in the case of selected representative mixtures of L-0-0 and H-0-0. As shown in Figure 3, the image was made by using differences in colors and brightness between the cement paste and BAA that were shown on the cross section of a specimen, and the corresponding area was calculated by using the software. The segregation of BAA was not found in any of the specimens, and the share of aggregate in each quarter zone was found to be generally similar. However, the specimen of group $\mathrm{H}$, the unit cement content of which is relatively high, shows a relatively high paste content compared with group L.

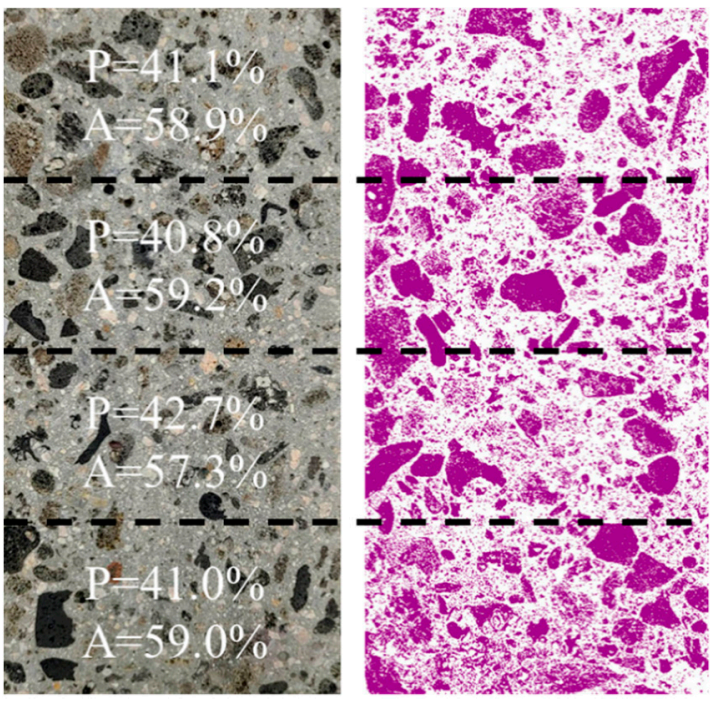

(a) L-0-0

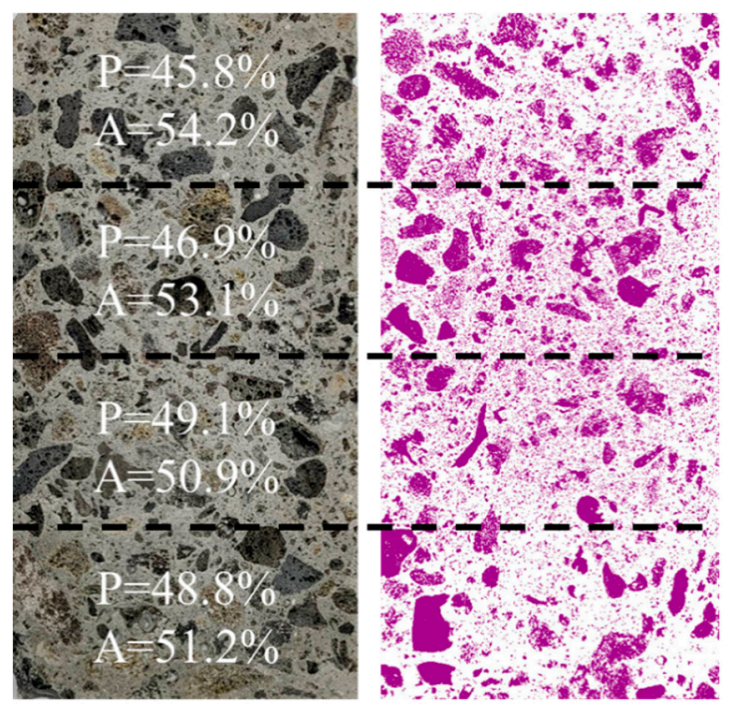

(b) $\mathrm{H}-0-0$

Figure 3. Distribution of lightweight aggregate particles with respect to the height of cylinder specimens (Note: P and A indicate cement matrix and bottom ash aggregate, respectively). 


\subsection{Compressive Strength at 28 Days $\left(f_{c u}\right)$}

Due to the low strength and porosity of the aggregate itself, CCBA shows relatively low compressive strength compared with NWC. Therefore, in the determination of concrete $f_{c d}$ in mix design, the type of aggregate also becomes a factor to consider, in addition to $W / C$ and unit cement contents.

When examining the compressive strength $\left(f_{c u}\right)$ of the specimens at 28 days, as shown in Table 4 , the L-100-100 mixture shows approximately 1.68 times higher strength than that of the L-0-0 mixture, depending on the type of aggregate used. It also shows a 1.5 times higher strength in group $\mathrm{M}$, and 1.26 times in group $\mathrm{H}$, respectively. It therefore appears that the influence of the type of aggregate decreases as W/C decreases (that is, as target strength increases). This means that some of the compressive strength reduction caused by the replacement of BAA can be offset by adjusting design factors such as $W / C$. Accordingly, to achieve a better $f_{c d}$ for CCBA, the design of a relatively low $W / C$ is desirable according to the replacement ratio of BA. In addition, as revealed by a number of previous studies, it is very advantageous in terms of strength development to add BA to concrete as fine aggregate, rather than as coarse aggregate. $[6,10,11]$. In the experiment, the strength deviations between \#-0-100 mixtures and \#-100-0 mixtures were found to be on average $8.9 \mathrm{MPa}$ (group L), 12.2 Mpa (group M), and 11.9 Mpa (group H), respectively. This is because cracking caused by external force occurred with the cracks passing through the BAA, and thus it acted as a greater weakness in coarse aggregates of large particle sizes [30].

The existing studies on the compressive strength of CCBA, although they are in early stages, have reported conflicting results. Some studies have reported that the use of BAA lowers compressive strength. Among them, Yüksel et al. [31] reported that when a 50\% replacement of fine aggregate and coarse aggregate was used, respectively, the compressive strength at 28 days was reduced from $52 \mathrm{Mpa}$ to $40 \mathrm{Mpa}$. Andrade et al. [32] found that when replacing BAA, the compressive strength drastically declined by up to $40 \%$. On the other hand, Singh and Siddique [6], Bai et al. [33], and Kim and Lee [34] reported that mixtures to which BAA is applied showed higher compressive strength than NWC. To explain this, they pointed out the pozzolanic reaction of BA or suggested that the mixing water was reduced due to the porosity of the aggregate. No study, however, has reported results showing that the strength increased when using coarse BAA.

In general, the compressive strength of concrete is highly correlated with the $W / C$ and air contents $\left(v_{A}\right)[35,36]$. In particularly, when using mixtures containing LWA such as BAA, $\rho_{c}$ should also be considered as an important factor. Lee et al. $[17,23]$ conducted non-linear multiple regression analysis (NLMR) on the basis of many studies, and included 39 A-LWAC mixtures and 308 S-LWAC mixtures. As a result, they proposed an equation for $f_{c u}$ prediction using parameters such as $W / C, v_{A}$, and $\rho_{c}$. Figure 4 shows a comparison between the equation proposed by Lee et al. [17] and the values obtained from the present experiment. The results of the present experiment, which include results using BAA, show a lower $f_{c u} / f_{0}$ than Lee et al., who used artificial LWA. This is attributable to specific physical properties such as the density of the aggregate used, strength, and percentage of voids. To predict the compressive strength of CCBA, which was evaluated in this study, with a good fit to the predicted values $\left(R^{2}=0.87\right.$, the equation proposed by Lee et al. needs to be revised as follows:

$$
\frac{f_{c u}}{f_{0}}=2.32 \cdot\left(\frac{\rho_{c}}{\rho_{0}}\right)^{1.23} \frac{C}{W}\left(\frac{1}{v_{A}}\right)^{0.09}
$$

where $f_{0}(=10 \mathrm{Mpa})$ is the reference value for the 28-day compressive strength of concrete, and $\rho_{0}$ $\left(=2300 \mathrm{~kg} / \mathrm{m}^{3}\right)$ is the reference value for the oven-dried density of concrete. 


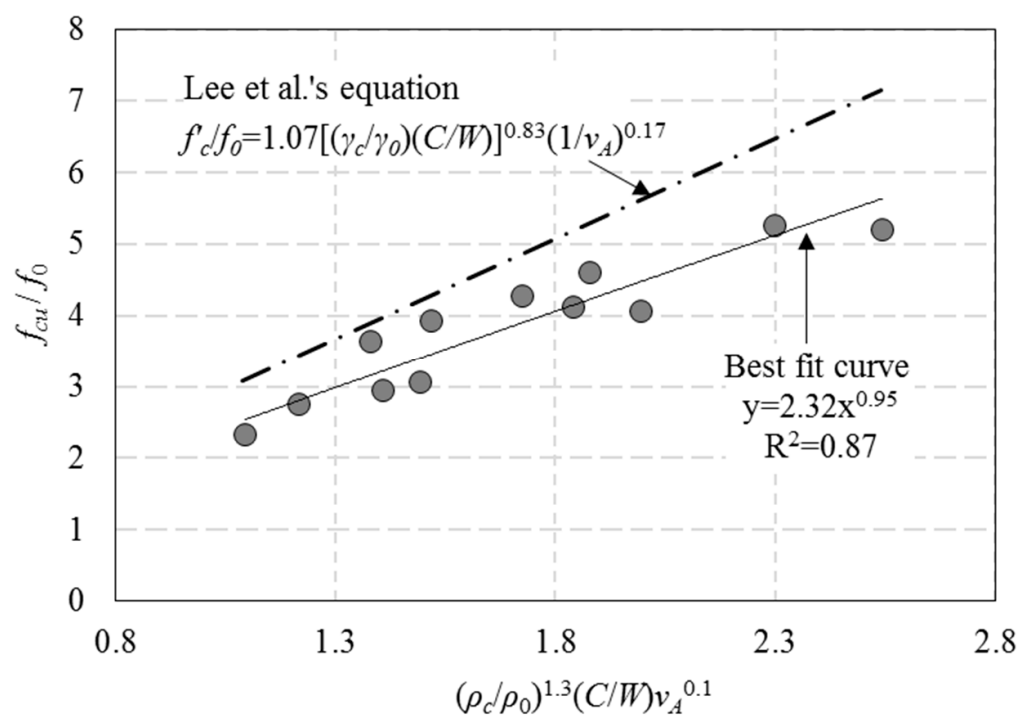

Figure 4. Regression analysis for the 28-day compressive strength of concrete.

\subsection{Compressive Strength Development}

Figure 5 shows the tendency of the compressive strength to increase with age, and includes the prediction curve proposed by the fib model [21]. The compressive strength $f_{\mathcal{c}}(t)$ of the specimens measured at age $t$ was normalized, with the 28-day compressive strength $f_{c u}$ as a reference. The compressive force development of all the specimens, including CCBA, occurs in the form of a parabolic curve, and the strength gain ratio gradually decreases over time. The strength gain ratio at three days relative to the 28-day strength was within 0.59-0.69 in all the specimens, so it was concluded that the differences were not significant according to W/C or aggregate types. However, the long-term strength gain ratios after 56 days were higher in the specimens of group L than in group $\mathrm{H}$. The mean strength gain ratios at 91 days relative to the 28-day strength were 1.16, 1.12, and 1.06 in groups $\mathrm{L}, \mathrm{M}$, and $\mathrm{H}$, respectively. All the gain ratios of long-term strength are within 1.05-1.2, the conventional values proposed for NWC by ACI 318 [24]. Regarding the similar or higher long-term strength gain ratios shown by CCBA compared with NWC, previous studies have shown that they are caused by the internal curing effect of aggregate [37] or the pozzolanic reaction of the fine BAA [38].

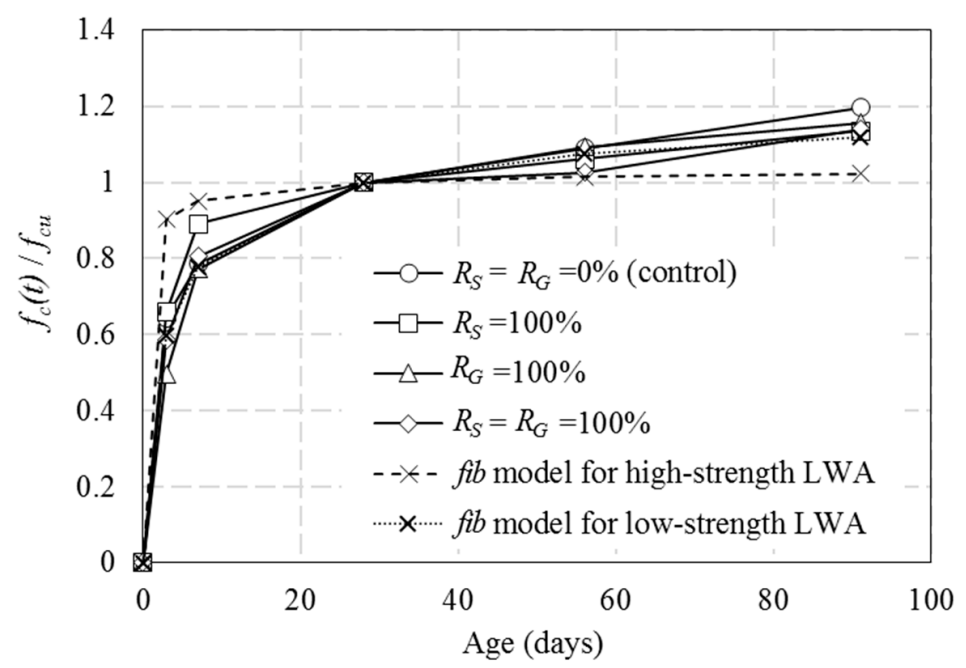

(a) $W / C=0.45$

Figure 5. Cont. 


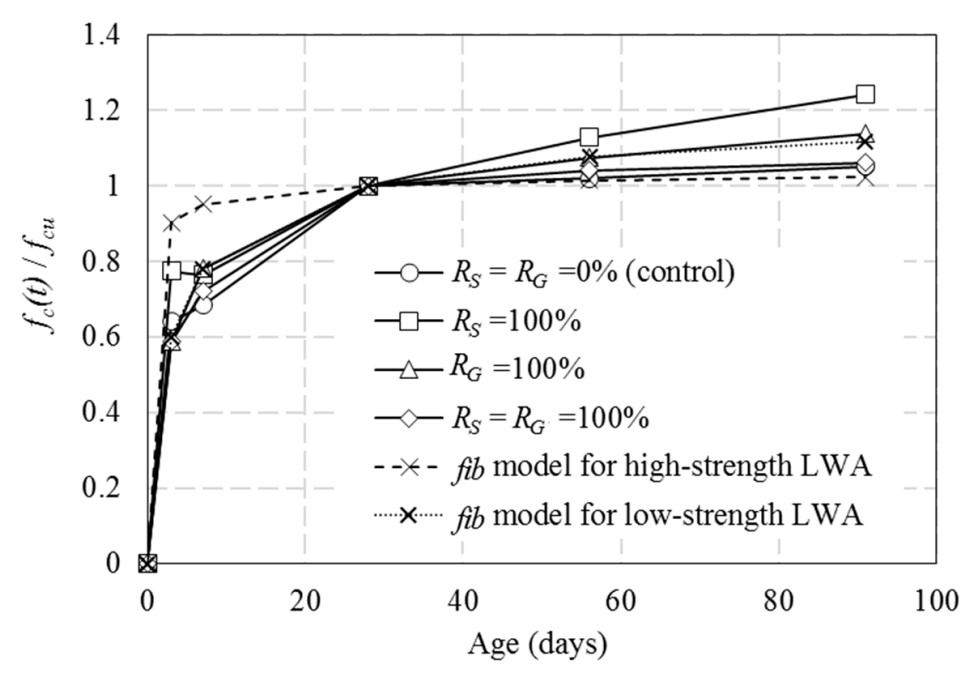

(b) $W / C=0.375$

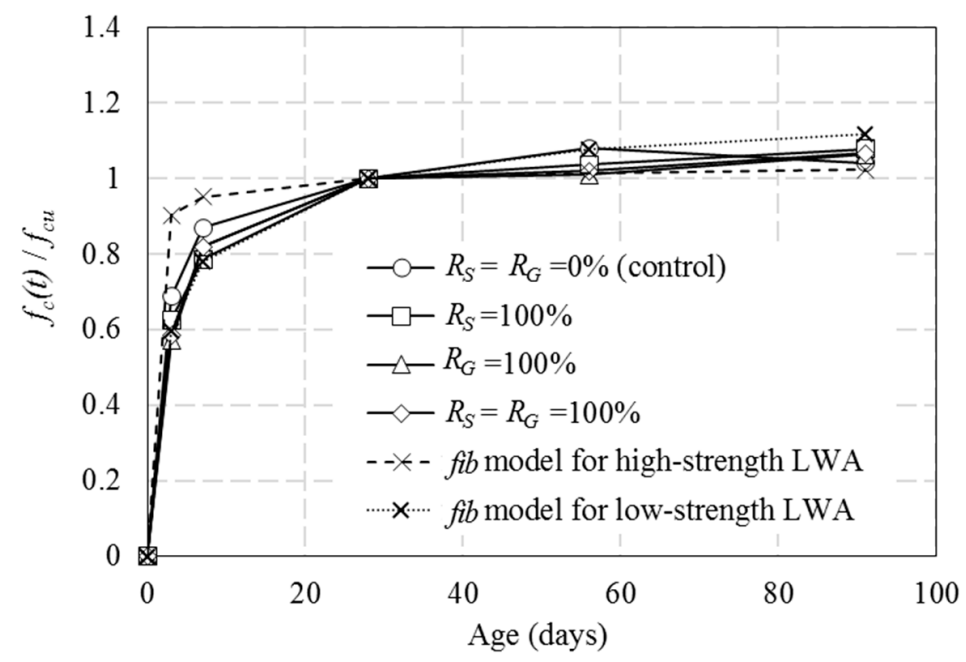

(c) $W / C=0.30$

Figure 5. Typical compressive strength gain ratio of concrete.

The fib model [21] adopts the variable $S_{l}$ showing the strength of aggregate as an important factor in predicting the compressive strength gain ratio of concrete by age, and so is mostly used in predictions for LWAC. For $S_{l}$, values of 0.05 in the case of high-strength LWA and 0.25 in the case of low-strength LWA are generally used, as seen in Equation (2). In addition, the fib model does not consider variation according to the replacement ratios of the LWA. The comparison shows that the results of the present experiment are close to the fib model (Equation (2)) in which $S_{l}=0.25$ is applied.

$$
f_{\mathcal{c}}(t)=\exp \left\{S_{l} \cdot\left[1-\left(\frac{28}{t}\right)^{0.5}\right]\right\} \cdot f_{\mathcal{c} u}
$$

where $t$ is the concrete age in days, and $S_{l}$ is a coefficient that depends on the strength of the LWA.

\subsection{Modulus of Elasticity $\left(E_{c}\right)$}

The modulus of elasticity $E_{c}$ for all the specimens measured at 28 days was within the range of approximately 18-28 GPa, and the means were found to be 21.0, 23.9, and 25.2 GPa for group L, 
group $\mathrm{M}$, and group $\mathrm{H}$, respectively. The influence of $W / C$ could be distinctly seen. A factor equally as significant as $W / C$ in determining the $E_{c}$ of concrete is the elastic modulus of the aggregate [39]. The type of coarse aggregate, that is, $R_{G}$, was found to have particularly important effects on the results of the experiment. The use of coarse BAA $\left(R_{G}=0 \%\right)$ led to the $E_{c}$ decreasing by approximately $12.6 \%(3.2 \mathrm{GPa})$ on average in group $\mathrm{M}$ and $17.9 \%$ (4.9 GPa) in group $\mathrm{H}$, compared with the use of crushed granite $\left(R_{G}=100 \%\right)$. On the other hand, the deviation of $E_{c}$ values according to the type of fine aggregate was rather low, $\pm 2.4 \%(0.6 \mathrm{GPa})$.

A number of studies have reported high correlations between the mixing ratio of BAA and the $E_{c}$ of the concrete. Andrade et al. [32] indicated that an increase in the mixing ratio of coarse BAA from $0 \%$ to $100 \%$ resulted in an abrupt decrease of $E_{c}$ by up to approximately $65 \%$, and Kurama et al. [40] stated that when using BAA for both fine aggregate and coarse aggregate, $E_{c}$ dropped by up to $15.1 \%$. When the BAA content is increased, more moisture accumulates around the aggregate than with natural aggregate because the porosity of the interfacial transition zone (ITZ) between the aggregate and cement paste increases. This ultimately results in a local increase in the W/C of the paste located around the aggregate, and thus the strength of the bond with the aggregate may be lowered [6,22].

Figure 6 shows the normalized modulus of elasticity, $E_{c} / \sqrt{f_{c u}}$, for concrete according to $\rho_{c}$, and, in the same figure, the predictive values of ACI 318 [24] and the fib model [21] and the values of the predictive model proposed by Lee et al. [23]. $E_{c}$ was normalized to exclude the effects of differences in strength, where $f_{c u}$ is the compressive strength at the same 28-day measurement point as the $E_{c}$ measurement. The prediction based on $\rho_{c}$ is reasonable because the $E_{c}$ of concrete is very sensitive to variations in the types and physical properties of the aggregate used [39]. In Figure 6, predictions by ACI and fib models show relatively close predictive values in the $\rho_{c}$ range of less than $1850 \mathrm{~kg} / \mathrm{m}^{3}$, but an excessive increase of $E_{c}$ in the range of $1950 \mathrm{~kg} / \mathrm{m}^{3}$ or above. The concrete $\rho_{c}$ value of 1850 $\mathrm{kg} / \mathrm{m}^{3}$ is also the boundary reference value by which ACI 213R [19] distinguishes between LWAC and NWC. On the other hand, comparison with the prediction proposed by Lee et al. [23] shows good agreement at most $\rho_{c}$ intervals.

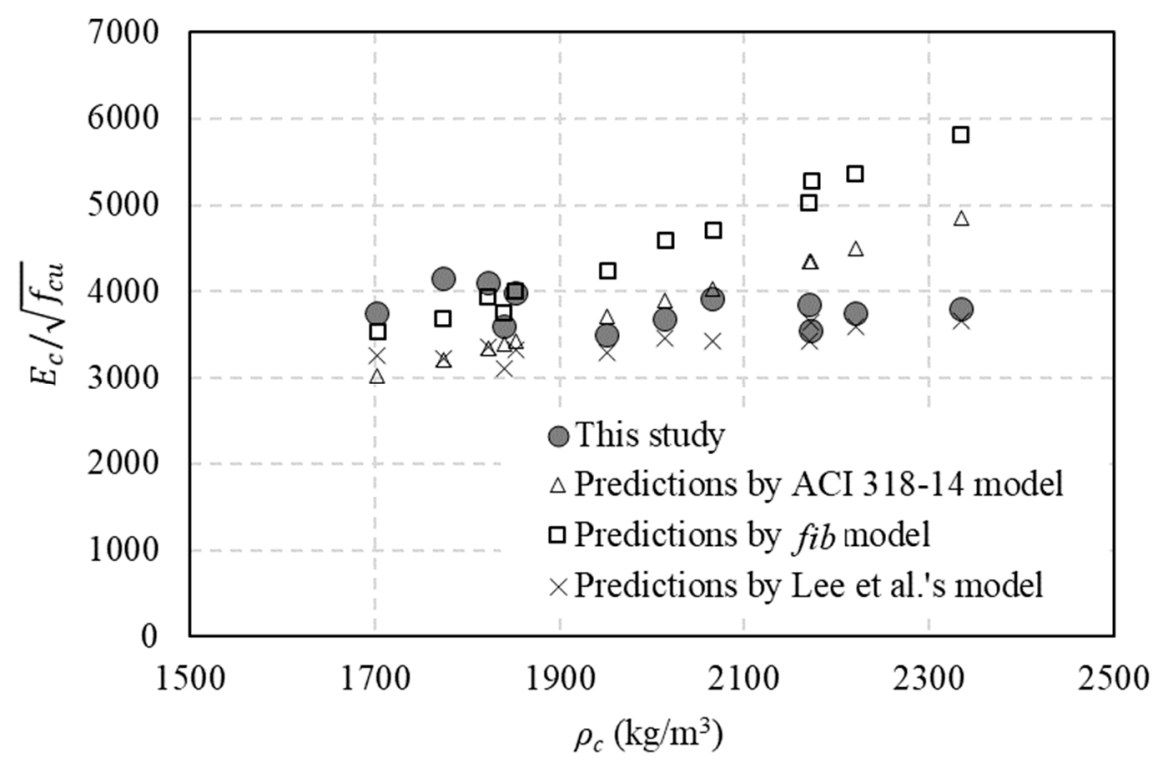

Figure 6. Effect of $\rho_{c}$ on the elasticity modulus.

\subsection{Tensile Resistance Capacity}

The splitting tensile strength $f_{s p} / \sqrt{f_{c}(91)}$ and modulus of rupture $f_{r} / \sqrt{f_{c}(91)}$ normalized by compressive strength at 91 days in order to evaluate the tensile resistance capacity of concrete are shown in Figures 7 and 8, respectively. The $f_{s p}$ and $f_{r}$ values were measured at the age of 91 days. The same figures also include predictions using ACI 318 [24], the fib model [21], and the design 
equation proposed by Lee et al. [23]. As a result of excluding effects on compressive strength by normalization, CCBA mixtures mostly showed slightly lower levels of tensile resistance capacity than NWC, but the differences were not significant. The fact that concrete specimens with different $\rho_{c}$ values show normalized values of similar levels may mean that the types of aggregate do not have great effects on the tensile resistance capacity. In fact, existing studies have reported that the quality of cement paste and ITZ were improved by the additional pozzolanic reaction of BAA, through which $f_{s p}$ was improved [11,41], or, to the contrary, found that a large amount of porosity in the ITZ caused an evident decline in tensile resistance [6]. However, it should be noted that the existing studies did not conduct normalization by compressive strength or cement content.

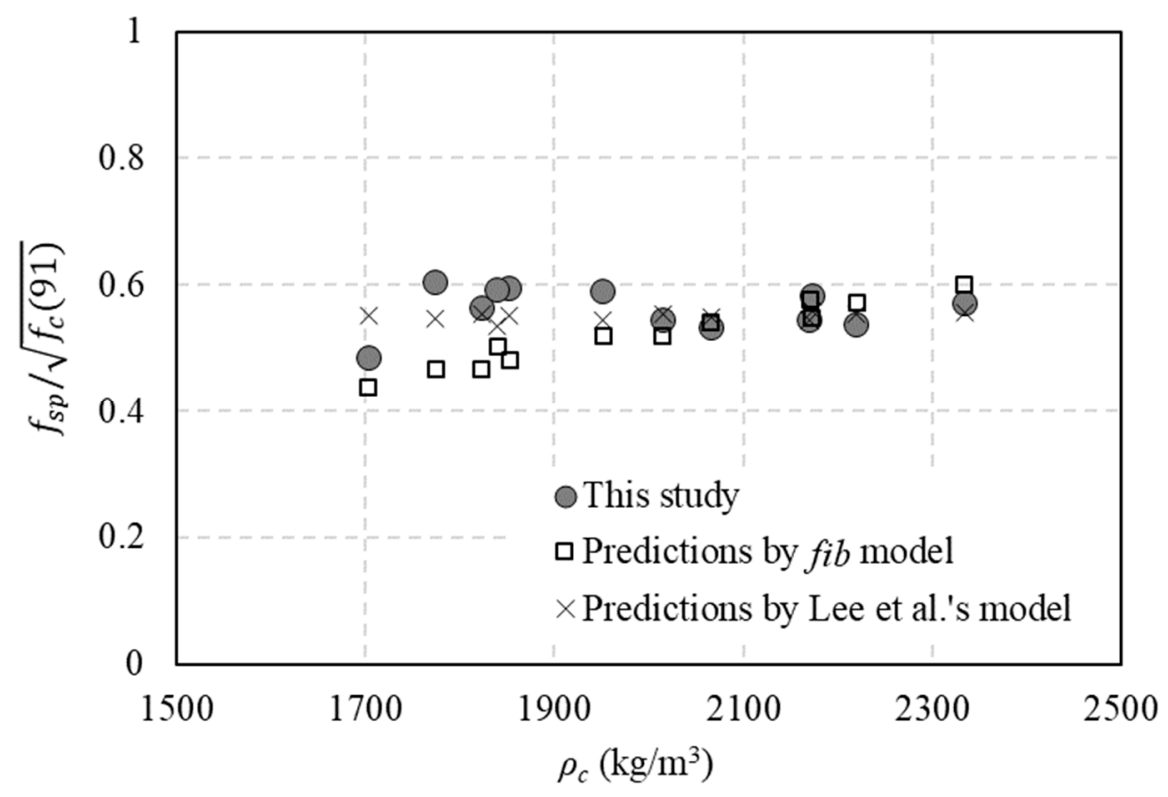

Figure 7. Effect of $\rho_{\mathcal{c}}$ on the splitting tensile strength.

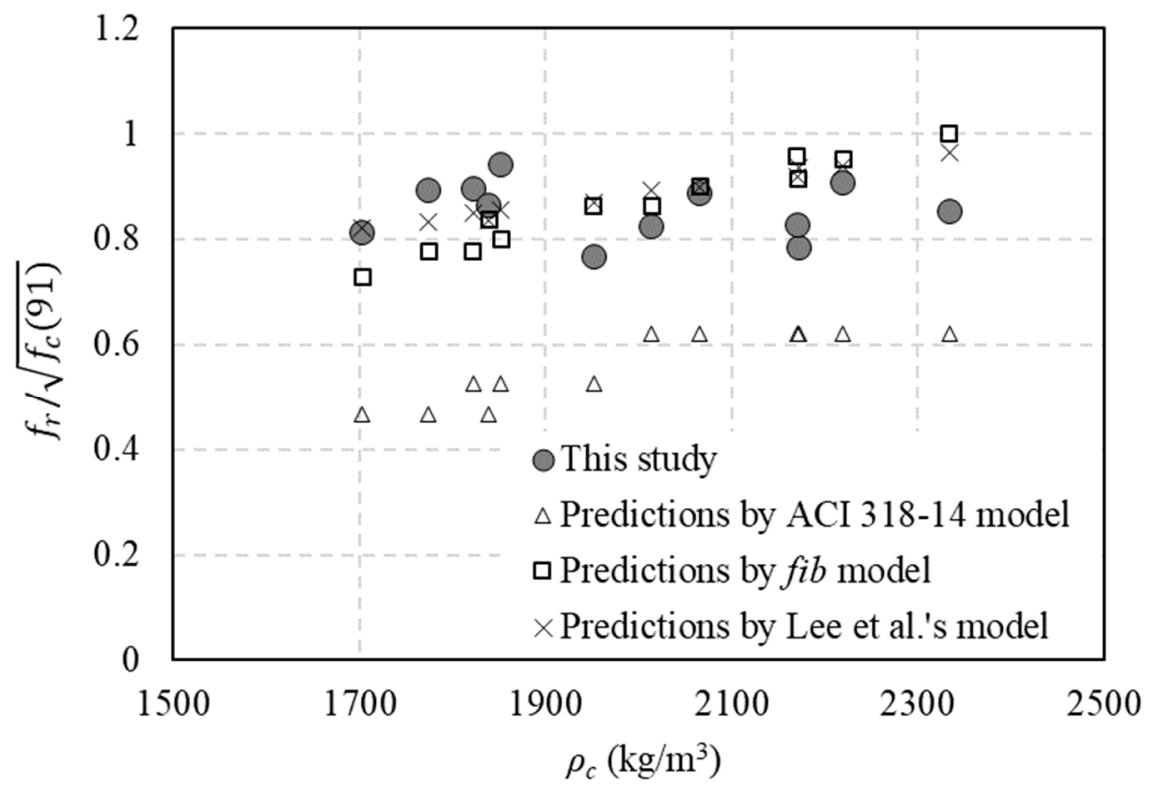

Figure 8. Effect of $\rho_{c}$ on the modulus of rupture.

The mean ratios between predictive values for $f_{s p} / \sqrt{f_{c}(91)}$ obtained from the fib model [21] and the equation of Lee et al. [23] and the experimental values were 0.93 and 0.98 , respectively. Those 
for $f_{r} / \sqrt{f_{c}(91)}$ were found to be 1.01 and 1.04, respectively, and so generally close agreement was observed. On the other hand, in Figure 8, the design equation of ACI 318 [24] is seen to estimate the $f_{r}$ of concrete very conservatively. The mean of ratios between the predictive values and the experimental values is 0.60 in group $L, 0.62$ in group $\mathrm{M}$, and 0.68 in group $\mathrm{H}$, showing large deviations.

\subsection{Shear Friction Strength}

The normalized shear friction strength $\tau / \sqrt{f_{c}(91)}$ showed a slight increase with the increase in $\rho_{c}$, as indicated in Figure 9. In particular, $\tau / \sqrt{f_{c}(91)}$ for A-LWAC $\left(R_{S}=R_{G}=0 \%\right)$ was only $87.8 \%$ on average, compared with NWC $\left(R_{S}=R_{G}=100 \%\right)$, and S-LWAC $\left(R_{S}=0 \%, R_{G}=100 \%\right)$ showed a relative level of $93.2 \%$. Some standards, including the domestic Korean Building Code [42], do not suggest a design standard for $\tau$, and even studies reporting the results of experiments on the mechanical properties of CCBA provide little data on shear failure. The $\tau$ and $\rho_{c}$ of lightweight aggregate concrete are mainly affected by the tensile resistance capacity. Therefore, the predictive model may vary greatly according to the types of aggregate used, and it is deemed urgent to establish relevant standards, given the tendency of increase in the utilization of BAA as concrete aggregate.

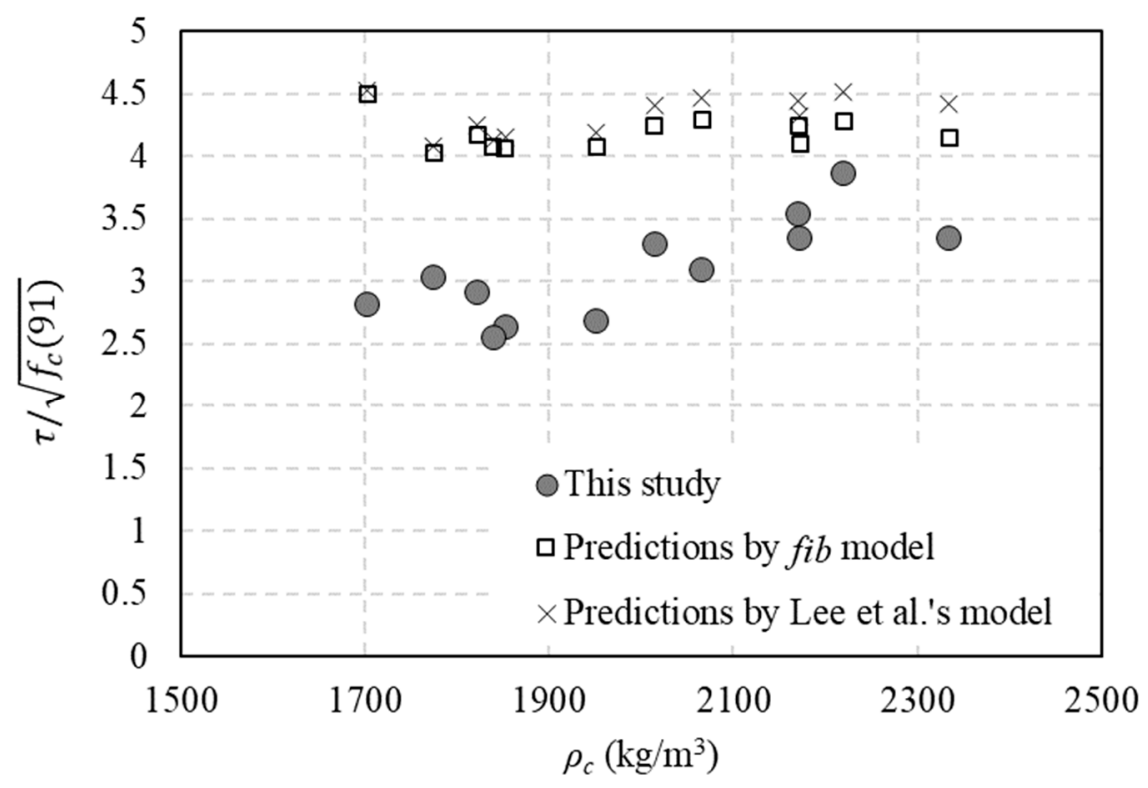

Figure 9. Effect of $\rho_{c}$ on the shear friction strength.

\section{Conclusions}

In order to use bottom ash, an industrial byproduct, as concrete aggregate, this study experimentally evaluated the effects of the types of fine aggregate and coarse aggregate and $W / C$ on the mechanical properties of concrete. The results of the experiment show that the density of concrete and the physical properties of aggregate should be considered as important factors for the performance design of concrete containing bottom ash aggregate. In particular, existing studies and databases on the use of bottom ash aggregate are not sufficient, which hinders the establishment of a reliable design standard. The following conclusions can be drawn from the comparison between the present experiment and the existing proposed code equations.

1. As a result of using bottom ash as fine and coarse aggregates, the initial slump shows a tendency to decrease irrespective of $W / C$. The rate of decline in workability was greater when applying the bottom ash as a fine aggregate of particles $600 \mu \mathrm{m}$ or less in size than as coarse aggregate.

2. The compressive strength showed a more significant decline when coarse aggregate of large particle sizes was replaced with bottom ash than when replacing fine aggregate. The equation 
for predicting the 28-day compressive strength of concrete containing bottom ash (Equation (1)), which was proposed by using important variables such as concrete density, $W / C$, and air contents, can be predicted rationally at the level of $R^{2}=0.87$.

3. When testing the concrete specimens using different types of aggregates, the characteristics of tensile resistance capacity and shear friction strength normalized by compressive strength generally showed a performance improvement with the increase in concrete density. In comparison with the predictive equation of the fib model, the ratios between the predictive values and experimental values were found to be within $0.93-1.01$, and so they were generally close to each other.

4. The existing model equation that predicts the modulus of elasticity on the basis of concrete density overestimates the modulus of elasticity in the case of specimens of $1840 \mathrm{~kg} / \mathrm{m}^{3}$ or above. In particular, the effects of the modulus of elasticity of the aggregate (particularly coarse aggregate) on the elasticity modulus of concrete are significant. However, data from mechanical experiments replacing coarse aggregate with bottom ash have been insufficient, and thus, it is necessary to establish a predictive equation of high reliability in the future on the basis of further testing.

Author Contributions: Conceptualization, Y.-H.K. and K.-H.Y.; formal analysis, H.-Y.K. and K.-H.Y.; funding acquisition, Y.-H.K.; investigation, H.-Y.K. and J.-S.H.; project administration, K.-H.Y.; resources, J.-S.H.; supervision, K.-H.Y.; writing-original draft, H.-Y.K.; writing—review and editing, H.-Y.K. All authors have read and agreed to the published version of the manuscript.

Funding: This research project was funded by the Korea South-East Power CO. of South Korea.

Conflicts of Interest: The authors declare no conflict of interest.

\section{References}

1. Park, S.B.; Jang, Y.I.; Lee, J.; Lee, B.J. An experimental study on the hazard assessment and mechanical properties of porous concrete utilizing coal bottom ash coarse aggregate in Korea. J. Hazard. Mater. 2009, 166, 348-355. [CrossRef]

2. Siddique, R. Utilization of coal combustion by-products in sustainable construction materials. Resour. Conserv. Recycl. 2010, 54, 1060-1066. [CrossRef]

3. Kurama, H.; Kaya, M. Usage of coal combustion bottom ash in concrete mixture. Constr. Build. Mater. 2008, 22, 1922-1928. [CrossRef]

4. Rathnayake, M.; Julnipitawong, P.; Tangtermsirikul, S.; Toochinda, P. Utilization of coal fly ash and bottom ash as solid sorbents for sulfur dioxide reduction from coal fired power plant: Life cycle assessment and applications. J. Clean. Prod. 2018, 202, 934-945. [CrossRef]

5. Kim, H.K. Utilization of sieved and ground coal bottom ash powders as a coarse binder in high-strength mortar to improve workability. Constr. Build. Mater. 2015, 91, 57-64. [CrossRef]

6. Singh, M.; Siddique, R. Effect of coal bottom ash as partial replacement of sand on properties of concrete. Resour. Conserv. Recycl. 2013, 72, 20-32. [CrossRef]

7. Kim, H.K.; Jang, J.G.; Choi, Y.C.; Lee, H.K. Improved chloride resistance of high-strength concrete amended with coal bottom ash for internal curing. Comput. Chem. Eng. 2014, 71, 334-343. [CrossRef]

8. Siddique, R. Use of municipal solid waste ash in concrete. Resour. Conserv. Recycl. 2010, 55, 83-91. [CrossRef]

9. Rafieizonooz, M.; Salim, M.R.; Mirza, J.; Hussin, M.W.; Khan, R.; Khankhaje, E. Toxicity characteristics and durability of concrete containing coal ash as substitute for cement and river sand. Constr. Build. Mater. 2017, 143, 234-246. [CrossRef]

10. Garcia, M.D.L.; Sousa-Coutinho, J. Strength and durability of cement with forest waste bottom ash. Constr. Build. Mater. 2013, 41, 897-910. [CrossRef]

11. Singh, M.; Siddique, R. Strength properties and micro-structural properties of concrete containing coal bottom ash as partial replacement of fine aggregate. Constr. Build. Mater. 2014, 50, 246-256. [CrossRef]

12. Singh, N.; Mithulraj, M.; Arya, S. Influence of coal bottom ash as fine aggregates replacement on various properties of concretes: A review. Resour. Conserv. Recycl. 2018, 138, 257-271. [CrossRef]

13. Rafieizonooz, M.; Mirza, J.; Salim, M.R.; Hussin, M.W.; Khankhaje, E. Investigation of coal bottom ash and fly ash in concrete as replacement for sand and cement. Constr. Build. Mater. 2016, 116, 15-24. [CrossRef] 
14. Muthusamy, K.; Hafizuddin, R.M.; Yahaya, F.M.; Sulaiman, M.A.; Mohsin, S.S.; Tukimat, N.N.; Omar, R.; Chin, S.C. Compressive strength performance of OPS lightweight aggregate concrete containing coal bottom ash as partial fine aggregate replacement. IOP Conf. Ser. Mater. Sci. Eng. 2018, 342. [CrossRef]

15. Yüksel, S.; Siddique, R.; Özkan, Ö. Influence of high temperature on the properties of concretes made with industrial by-products as fine aggregate replacement. Constr. Build. Mater. 2011, 25, 967-972. [CrossRef]

16. Kasemchaisiri, R.; Tangtermsirikul, S. Properties of self-compacting concrete incorporating bottom ash as a partial replacement of fine aggregate. Sci. Asia 2008, 34, 87-95. [CrossRef]

17. Lee, K.H.; Yang, K.H.; Mun, J.H.; van Tuan, N. Effect of Sand Content on the Workability and Mechanical Properties of Concrete Using Bottom Ash and Dredged Soil-based Artificial Lightweight Aggregates. Int. J. Concr. Struct. Mater. 2019, 13, 115-127. [CrossRef]

18. Lee, K.H.; Yang, K.H.; Yoon, H.S. Shrinkage strains of lightweight aggregate concrete using expanded bottom ash and dredged soil granules. Constr. Build. Mater. 2018, 188, 934-945. [CrossRef]

19. ACI Committee 213. Guide for Structural Lightweight Aggregate Concrete (ACI 213R-14); American Concrete Institute: Farmington Hills, MI, USA, 2014.

20. ASTM C330/C330M. Standard Specification for Lightweight Aggregates for Structural Concrete; ASTM International: West Conshohocken, PA, USA, 2017.

21. Fib Model Code for Concrete Structures 2010; International Federation for Structural Concrete (fib): Lausanne, Switzerland, 2010.

22. Nikbin, I.M.; Rahimi, S.R.; Allahyari, H.; Damadi, M. A comprehensive analytical study on the mechanical properties of concrete containing waste bottom ash as natural aggregate replacement. Constr. Build. Mater. 2016, 121, 746-759. [CrossRef]

23. Lee, K.H.; Yang, K.H.; Mun, J.H.; Kwon, S.J. Mechanical properties of concrete made from different expanded lightweight aggregates. Aci Mater. J. 2019, 116, 9-19. [CrossRef]

24. ACI Committee 318. Building Code Requirement for Structural Concrete (ACI 318-14); American Concrete Institute: Farmington Hills, MI, USA, 2014.

25. ASTM C150/C150M. Standard Specification for Portland Cement; ASTM International: West Conshohocken, PA, USA, 2011.

26. ASTM C143/C143M-20. Standard Test Method for Slump of Hydraulic-Cement Concrete; ASTM International: West Conshohocken, PA, USA, 2015.

27. ASTM C231/C231M. Standard Test Method for Air Content of Freshly Mixed Concrete by the Pressure Method; ASTM International: West Conshohocken, PA, USA, 2017.

28. ASTM C469/C469M. Standard Test Method for Static Modulus of Elasticity and Poisson's Ratio of Concrete in Compression; ASTM International: West Conshohocken, PA, USA, 2014.

29. Cheriaf, M.; Rocha, J.C.; Péra, J. Pozzolanic properties of pulverized coal combustion bottom ash. Cem. Concr. Res. 1999, 29, 1387-1391. [CrossRef]

30. Nikbin, I.M.; Beygi, M.H.; Kazemi, M.T.; Amiri, J.V.; Rahmani, E.; Rabbanifar, S.; Eslami, M. A comprehensive investigation into the effect of aging and coarse aggregate size and volume on mechanical properties of self-compacting concrete. Mater. Des. 2014, 59, 199-210. [CrossRef]

31. Yüksel, I.; Bilir, T.; Özkan, Ö. Durability of concrete incorporating non-ground blast furnace slag and bottom ash as fine aggregate. Build. Environ. 2007, 42, 2651-2659. [CrossRef]

32. Andrade, L.B.; Rocha, J.C.; Cheriaf, M. Influence of coal bottom ash as fine aggregate on fresh properties of concrete. Constr. Build. Mater. 2009, 23, 609-614. [CrossRef]

33. Bai, Y.; Darcy, F.; Basheer, P.A.M. Strength and drying shrinkage properties of concrete containing furnace bottom ash as fine aggregate. Constr. Build. Mater. 2005, 19, 691-697. [CrossRef]

34. Kim, H.K.; Lee, H.K. Use of power plant bottom ash as fine and coarse aggregates in high-strength concrete. Constr. Build. Mater. 2011, 25, 1115-1122. [CrossRef]

35. Bogas, J.A.; Gomes, A. A simple mix design method for structural lightweight aggregate concrete. Mater. Struct. 2013, 46, 1919-1932. [CrossRef]

36. Yang, K.H.; Kim, G.H.; Choi, Y.H. An initial trial mixture proportioning procedure for structural lightweight aggregate concrete. Constr. Build. Mater. 2014, 55, 431-439. [CrossRef]

37. Collins, F.; Sanjayan, J.G. Strength and shrinkage properties of alkali-activated slag concrete containing porous coarse aggregate. Cem. Concr. Res. 1999, 29, 607-610. [CrossRef] 
38. Jaturapitakkul, C.; Cheerarot, R. Development of bottom ash as pozzolanic material. J. Mater. Civ. Eng. 2003, 15, 48-53. [CrossRef]

39. Neville, A.M. Properties of Concrete, 4th ed.; Addison Wesley Longman limited: Essex, UK, 1997.

40. Kurama, H.; Topçu, I.B.; Karakurt, C. Properties of the autoclaved aerated concrete produced from coal bottom ash. J. Mater. Process. Technol. 2009, 209, 767-773. [CrossRef]

41. Raju, R.; Paul, M.M.; Aboobacker, K.A. Strength Performance of Concrete Using Bottom Ash As Fine Aggregate. Int. J. Res. Eng. Technol. 2014, 2, 111-122.

42. Korea Construction Standard Center (KCSC). Korean Building Code; KCSC: Goyang-si, Korea, 2016.

Publisher's Note: MDPI stays neutral with regard to jurisdictional claims in published maps and institutional affiliations.

(C) 2020 by the authors. Licensee MDPI, Basel, Switzerland. This article is an open access article distributed under the terms and conditions of the Creative Commons Attribution (CC BY) license (http://creativecommons.org/licenses/by/4.0/). 